\title{
Diversidade MORfológica e formas de VIDA das ARaCEae no Parque Estadual do Rio Doce, Minas Gerais
}

\author{
Livia Godinho Temponi ${ }^{1}$, Flávia Cristina Pinto Garcia ${ }^{2}$, \\ Cássia Mônica Sakuragui ${ }^{3}$ \& Rita Maria de Carvalho-Okano ${ }^{2}$
}

\section{RESUMO}

(Diversidade morfológica e formas de vida das Araceae no Parque Estadual do Rio Doce, Minas Gerais) Araceae apresenta uma morfologia e terminologia específica, que pode ocasionar dificuldades de compreensão. Além disso, alguns conceitos adotados para a família, são discordantes entre os especialistas do grupo. Para uma compreensão profunda de tal morfologia, bibliografias especializadas são requeridas. No levantamento das espécies de Araceae do Parque Estadual do Rio Doce (PERD) foram encontradas 13 espécies e oito gêneros (incluindo aqueles com maior diversidade específica, Anthurium e Philodendron). Uma síntese ilustrada da morfologia e terminologia dos gêneros e espécies do PERD é apresentada, visando uma melhor compreensão da morfologia e taxonomia geral da família.

Palavras-chave: Araceae, morfologia, formas de vida.

\section{Abstract}

(Morphological diversity and life forms in Araceae from the Rio Doce State Park, Minas Gerais) The use of specialized terms for some morphological features in Araceae can cause problems in understanding for the general reader and there are not always agreements among taxonomic specialists of the correct usage of some descriptive terminologies. For a complete understanding of this morphology, specialized literature must be consulted. In an inventory of Araceae from the Rio Doce State Park (PERD) the morphology of 13 species and 8 genera was studied (including Anthurium and Philodendron). An illustrated overview of the morphology and terminology of the genera and species from the PERD is presented aiming a better understanding of the morphology and taxonomy of the family.

Key-words: Araceae, morphology, life forms.

\section{INTRODUÇÃO}

Araceae pode ser caracterizada por apresentar inflorescência em espádice, associada a uma bráctea, a espata, flores pequenas, actinomorfas, sem bractéolas, gineceu gamocarpelar, fruto baga e a presença, até onde é conhecido, de taninos (Grayum 1990).

As Araceae são mais diversas e abundantes em áreas tropicais úmidas, onde são encontradas em uma grande variedade de formas de vida. De acordo com Grayum (1990) aproximadamente $70 \%$ das espécies de Araceae são epífitas, hemi-epífitas e trepadeiras, apesar de muitas espécies ocorrerem como terrestres ou aquáticas. Croat (1988) relatou que as plantas epífitas (incluindo as hemi-epífitas) crescem em árvores ou arbustos e por isso, geralmente, ocorrem em florestas de áreas úmidas, podendo ser indicadoras de umidade de uma determinada região; os gêneros terrestres, por outro lado, apresentam-se mais diversos ecologicamente, ocorrendo tanto em hábitat úmido quanto muito seco. No neotrópico, há um total de 22 gêneros estritamente terrestres e muitos destes são bem adaptados para se desenvolverem em condições extremas de baixa temperatura ou seca, apresentando um período de

Artigo recebido em 09/2004. Aceito para publicação em 05/2005.

${ }^{1}$ Programa de Pós-Graduação em Botânica da Universidade Federal de Viçosa, Instituto de Biologia Vegetal, 36570 000, Viçosa, MG, Brasil. Endereço atual: Universidade de São Paulo, Departamento de Botânica, IB, Caixa Postal 11461, 05422-970, São Paulo, SP. E-mail: liviatemponi@bol.com.br

${ }^{2}$ Universidade Federal de Viçosa, Instituto de Biologia Vegetal, CEP 36.570-000, Viçosa, MG, Brasil.

${ }^{3}$ Universidade Estadual de Maringá, Av. Colombo 3690, CEP 80.001-970, Maringá, PR, Brasil. 
crescimento interrompido quando sob condições severas (Croat 1988).

A circunscrição das subfamílias de Araceae tem apresentado modificações desde Engler \& Krause (1920). Nesta obra, os autores descrevem: Pothoideae, Monsteroideae, Lasioideae, Calloideae, Philodendroideae, Colocasioideae, Aroideae e Pistioideae. Posteriormente, Grayum (1990) circunscreve Pothoideae (incluindo Monsteroideae), Calloideae (incluindo Philodendroideae) Aroideae (incluindo Pistioideae) e mantém Lasioideae e Colocasioideae. Trabalhos mais recentes como a filogenia de French et al. (1995) baseada em dados moleculares (cpDNA) e o de Mayo et al. (1997) que se baseia na utilização de 63 caracteres morfoló-gicos, incluindo anatômicos, propõem sete subfa-mílias monofiléticas; Gymnostachydoideae, Orontioideae, Pothoideae, Monsteroideae, Lasioideae, Calloideae e Aroideae. A subfamília Aroideae senso French et al. (1995) e Mayo et al. (1997) inclui duas outras; Colocasioideae e Philodendroideae, além de Lemnaceae, que foram tratadas como distintas nos sistemas de classificação anteriores. Os padrões de colênquima propostos por Gonçalves et al. (2004) não suportam a distinção de Colocasioideae, Aroideae e Philodendroideae, corroborando com as hipóteses de French et al. (1995). Através da compilação de dados anatômicos Keating (2004), propõe o mais recente tratamento para a família, descreve uma nova subfamília; Schismatoglottidoideae e mantém Gymnostachydoideae, Orontioideae, Pothoideae, Lasioideae, Calloideae, Philodendroideae, Lemnoideae e Aroideae como subfamílias distintas.

A grande plasticidade fenotípica e a heteroblastia (morfologia do caule e das folhas refletindo as diferenças das fases de desenvolvimento), são freqüentes na família como um todo. Na maioria das vezes, plantas juvenis podem produzir folhas com formas distintas das presentes em plantas adultas
(Croat 1988). Esta grande variabilidade morfológica e a carência de observações no campo contribuem para gerar descrições incompletas, não abrangendo as variações morfológicas que podem ocorrer na população, ocasionando, muitas vezes, enganos na identificação das espécies ou proliferação de nomes. Além disso, muitas espécies são pouco coletadas em função do porte avantajado e das inflorescências carnosas, difíceis de serem tratadas para uma boa herbori-zação.

As Araceae, pela complexidade de sua sistemática e pelas peculiaridades morfológicas de suas folhagens e inflorescências, têm despertado o interesse de muitos botânicos. Entretanto, sua morfologia bastante diferenciada dos demais grupos vegetais resulta em uma nomenclatura própria, dificultando sua compreensão. Levando-se em conta os fatores relatados, este trabalho foi realizado com o intuito de informar sobre a morfologia de alguns gêneros da família, freqüentes na flora brasileira e ocorrentes no PERD, visando contribuir para uma melhor compreensão da morfologia das Araceae em leituras posteriores.

\section{Material e Métodos}

Durante o levantamento florístico das Araceae do Parque Estadual do Rio Doce (Temponi 2001), a maior área de floresta tropical contínua de Minas Gerais (35.973 ha), representantes férteis foram coletados e preparados de acordo com as técnicas específicas para espécimes da família (Croat 1985). Posteriormente, foram incluídos no herbário VIC (sigla segundo Holmgren et al. 1990).

As inflorescências foram fixadas em FAA $50 \%$ e conservadas em álcool $70 \%$, para análise posterior e ilustrações. Mudas de todas as espécies foram coletadas para o cultivo e, foram mantidas no Horto Botânico do Departamento de Biologia Vegetal da UFV, possibilitando-nos acompanhar seu desenvolvimento e observar as variações morfológicas das mesmas. Durante as coletas, também foram realizadas observações sobre a 
morfologia, período de floração, ambiente de ocorrência e sua posição no vegetal suporte.

Para a terminologia das partes vegetativas e reprodutivas foram utilizados os trabalhos de Madison (1977), Radford et al. (1979), Croat \& Bunting (1979) e Mayo (1991). Para a lâmina foliar com extensões em cada lado da inserção do pecíolo, esta foi dividida em divisão anterior e divisões posteriores conforme definido por Mayo et al. (1997). Para os padrões de venação e os tipos básicos de inflorescência adotou-se Mayo (1991) e Mayo et al. (1997).

Estas espécies foram ilustradas, visando elucidar a morfologia do grupo. As ilustrações foram realizadas, a partir de material cultivado e/ou fixado em FAA 50\%, com auxílio de estereomicroscópio, para estruturas menores.

\section{Resultados E discussão}

Uma representativa diversidade dos caracteres vegetativos (Tabela 1) e reprodutivos (Tabela 2) das Araceae do Brasil pôde ser verificada nas espécies encontradas no Parque Estadual do Rio Doce (PERD), Minas Gerais.

Das nove subfamílias sensu Keating (2004), seis ocorrem no Brasil. As três com maior número de gêneros e espécies ocorrem na área de estudo (Tabela 1): Pothoideae (com 4 gêneros no PERD), Philodendroideae (2 gêneros) e Aroideae (2 gêneros). Apenas Schismatoglottidoideae, Lasioideae e Lemnoideae, que geralmente são repre-sentadas por poucos gêneros no Brasil não foram tratadas aqui. A grande diversidade morfológica apontada neste estudo, se deve ao fato de que $21 \%$ dos gêneros de Araceae que ocorrem no Brasil foram encontrados no PERD.

As Araceae podem ocorrer como hemiepífitas, possuindo dois tipos de raízes: as alimentadoras, para a absorção de água e nutrientes do solo, e as âncoras (grampi-formes), para fixação no vegetal suporte (Fig. 1a). O hábito hemi-epífita pôde ser verificado em Philodendron vargealtense (Fig. 1a), assim como para a maioria das espécies do PERD. São tidas como hemi-epífitas primárias ou secundárias (Croat 1988), pois podem iniciar seu desenvolvimento como terrestre, germinando no solo e posteriormente ocupando um vegetal suporte e perdendo conexão com o chão (hemi-epífita secundária) ou inicia seu desenvolvimento como epífita, germinando no vegetal suporte e, posteriormente, suas raízes alimentadoras projetam-se até o solo da mata (hemi-epífita primária). Uma epífita se difere tanto da hemi-epífita primária ou secundária porque esta nunca se conecta ao solo, como observado para Anthurium scandens (Figura 1b). Esta espécie foi encontrada apenas duas vezes no PERD e estes indivíduos apresentavam suas raízes associadas às de Bromeliaceae e Cactaceae, formando um ninho de formigas.

As epífitas e hemi-epífitas representam cerca de $80 \%$ das espécies de Araceae do PERD (Tabela 1). A grande porcentagem de espécies com estas formas de vida nos indica que o Parque Estadual do Rio Doce é uma floresta úmida. Croat (1988) relatou que as plantas epífitas (incluindo as hemi-epífitas) crescem em árvores ou arbustos e por isso, geralmente, ocorrem em florestas de áreas úmidas, podendo ser indicadoras de umidade de uma determinada região. Embora em uma boa parte do ano a precipitação no Parque seja baixa (Temponi 2001), possivelmente, a ocorrência de 38 a 44 lagoas cobrindo cerca de $6 \%$ da sua área total (aproximadamente 2.150 ha), mantém a umidade da região.

Uma outra forma de vida marcante é a geófita, com caule tuberoso ou rizomatoso, subterrâneo, como ocorre em Asterostigma luschnathianum (Fig. 1c). Estas plantas geralmente exibem uma sazonalidade marcante com uma fase de crescimento e outra de dormência, podendo perder sua única folha.

As espécies de Rhodospatha e Xanthosoma do PERD apresentam a forma 


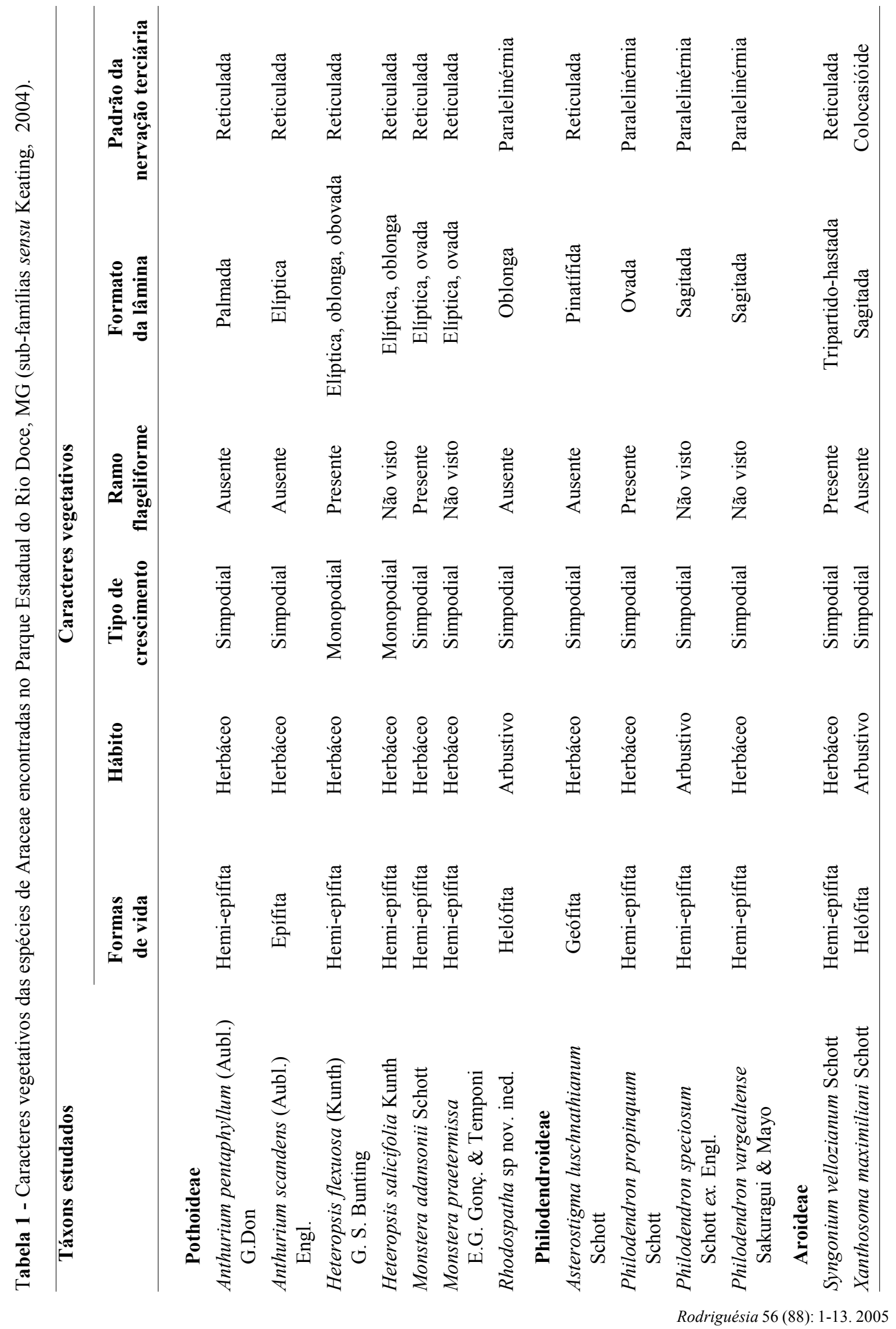




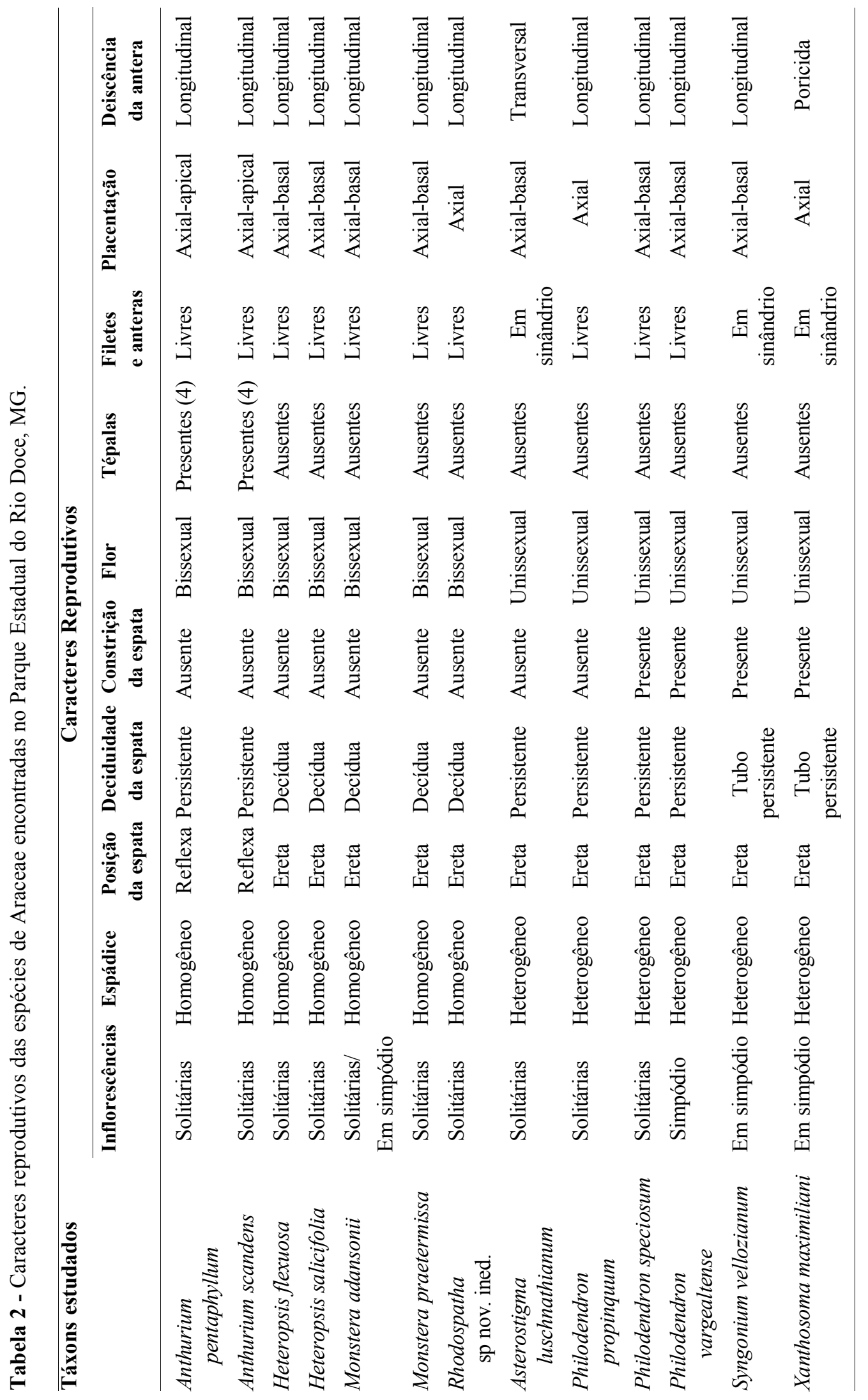

Rodriguésia 56 (88): 1-13. 2005 
vida helófita como definido por Mayo et al. (1997), pois ocorrem em ambientes brejosos ou alagáveis, pelo menos, nos períodos de maiores precipitações.

Para alguns autores como Mayo et al. (1997), espécies maiores podem apresentar o hábito arbustivo com o eixo principal, formando um caule carnoso, como em Alocasia e Xanthosoma (Fig. 1d), ou fibroso, como em Philodendron (Fig. 1e). No PERD, o hábito arbustivo foi verificado para Philodendron speciosum, Rhodospatha sp. e Xanthosoma maximiliani (Tabela 1). Embora o padrão de crescimento em diâmetro e o porte sejam muito distintos dos verificados nas espécies arbóreas e arbustivas de dicotiledôneas, o termo arbustivo vem sendo usado para algumas espécies de Araceae, que apresentam hábito semelhante ao arbóreo. Nesta situação peculiar, o caule não se ramifica e ocorre um aumento do diâmetro devido à produção de meristemas apicais maiores em unidades simpodiais sucessivas.

O caule, quando aéreo, é bastante variável e dentro da família, ele pode ser taxonomicamente útil. Trabalhos clássicos como os de Ray (1987a, 1987b) que discutem e definem a diversidade da organização do caule e tipos de folha na família devem ser estudados para um melhor entendimento sobre este tópico. De uma forma simplificada podemos dizer que em muitos gêneros, o caule maduro é um simpódio composto de unidades simpodiais como em Anthurium scandens (Fig. 1f). Cada unidade simpodial começa com um profilo (primeira folha), seguido de um número variável de catafilos (folhas reduzidas) e eufilos, de acordo com o grupo e, termina com uma inflorescência (Fig. 1f) ou inflorescência abortada. Neste tipo de crescimento simpodial o ramo principal é substituído pelo ramo lateral. O tipo de crescimento monopodial foi relatado para Heteropsis e para muitos representantes da tribo Potheae. O tipo de crescimento monopodial foi verificado para as espécies de Heteropsis encontradas no PERD (Fig. 1g). Neste tipo de cres- cimento, as inflorescências ocorrem em ramos laterais e o ramo principal continua seu crescimento, aparentemente, indeterminado.

Caules especializados para a reprodução vegetativa, chamados de ramos flageliformes, têm sido observados em vários gêneros como Philodendron, Syngonium, Heteropsis (Mayo et al. 1997) e Monstera (Andrade \& Mayo 1998). Os ramos flageliformes também ocorrem em algumas espécies de Rhodospatha como $R$. latifolia Poepp. \& Endl. e $R$. oblongata Poepp. \& Endl. (ambas hemiepífitas), mas não foram observados na espécie de Rhodospatha (uma helófita), que ocorre no PERD. Eles consistem de ramos nos quais os entrenós tornam-se muito mais longos e esguios do que a parte do caule florífero e as folhas tornam-se reduzidas em tamanho, ficando semelhante a catafilos ou escamas. Estes ramos crescem rapidamente e ocupam novas árvores suporte, nas quais, posteriormente, caules floríferos se desenvolverão. Durante o levantamento florístico das Araceae do PERD o desenvolvimento de ramos flageliformes foi verificado em quatro espécies (Tabela 1): Heteropsis flexuosa, Monstera adansonii, Philodendron propinquum e Syngonium vellozianum (Fig. 1h).

O termo bainha peciolar nem sempre é utilizado para a família. Para Mayo et al. (1997) a folha é claramente diferenciada em bainha peciolar, pecíolo e lâmina expandida. Porém, de acordo com a definição de Madison (1977), por ser difícil determinar os limites de cada estrutura, a bainha e o pecíolo juntos foram tratados de pecíolo (Fig. 2a), que pode ser descrito como sendo invaginado, alado (Fig. 2e), canaliculado ou com uma bainha na base. A inserção do pecíolo é normalmente anular, porque este envolve o entrenó, exceto em algumas espécies, como a maioria dos Heteropsis, nas quais a inserção do pecíolo não chega a envolver o caule.

O tamanho e a forma da lâmina são bastante diversos dentro da família e nas espécies encontradas no PERD foi possível obser- 


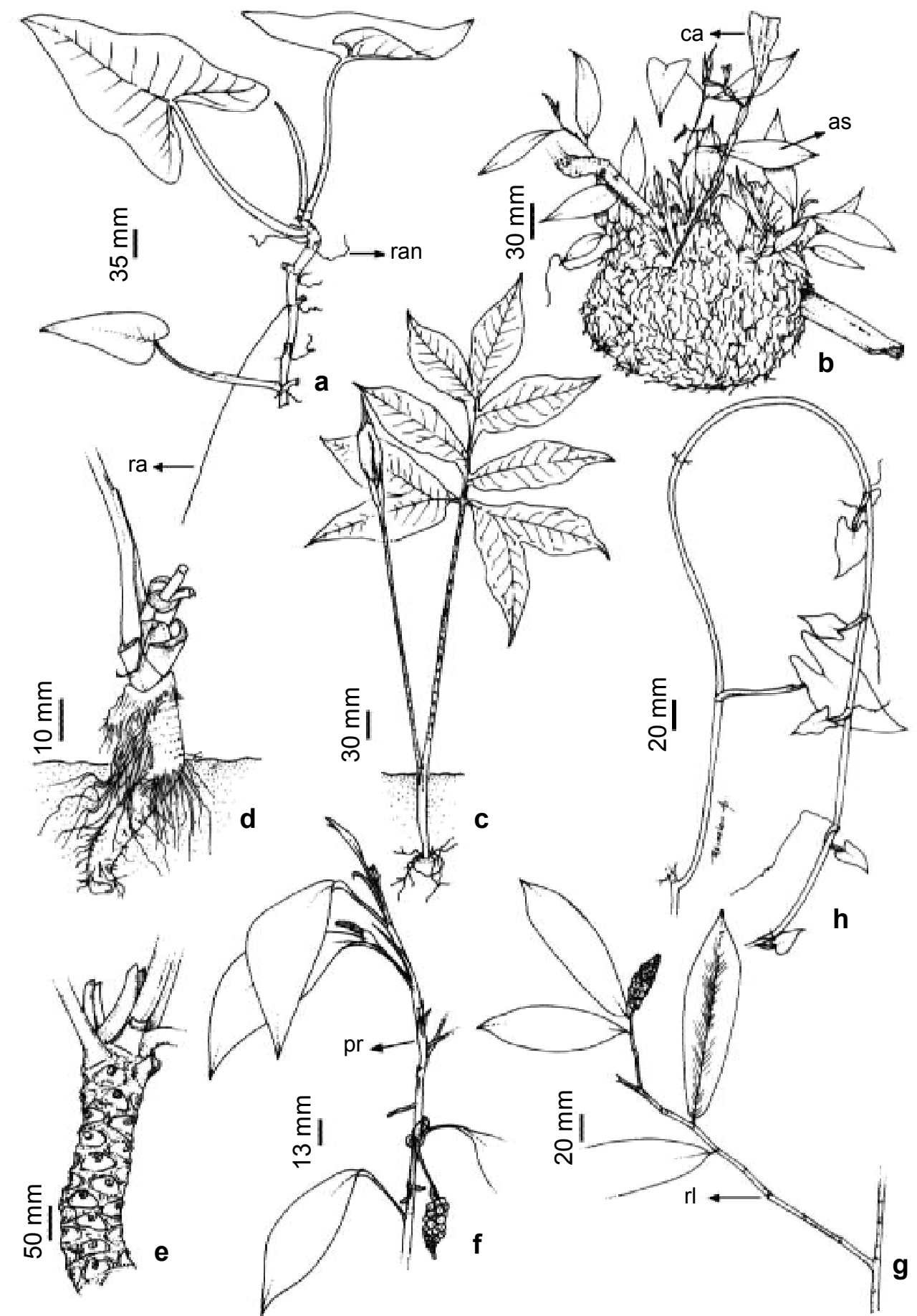

Figura 1 - Hábitos e tipos de crescimento de caule: a. Philodendron vargealtense: erva, hemi-epífita, ra=raiz alimentadora e ran=raiz âncora (Temponi 223); b. epífita, raízes formando ninho de formigas, ca=Cactaceae, as=Anthurium scandens; (Temponi 193); c. Asterostigma luschnathianum: erva, geófita de caule rizomatoso, subterrâneo (Temponi 221); d. Xanthosoma maximiliani: arborescente, helófita de caule tuberoso, parcialmente subterrâneo (Temponi 178); e. Philodendron speciosum: arborescente, hemi-epífita (Temponi 179); f. Anthurium scandens: caule com crescimento simpodial, pr=profilo (Temponi 193); g. Heteropsis flexuosa: caule com crescimento monopodial, rl=ramos laterais (Temponi 138); h. Syngonium vellozianum: ramo flageliforme (Temponi 224). 
var lâminas foliares de diminuta a gigante, de sim-ples obovada (Fig. 2b), elíptica (Fig. 2c), ovada (Figs. 2d, g, h), sagitada (Fig. 2f), tripartido-hastada (Fig. 2j) e pinatífida (Fig. 21) a palmada (Fig. 2n).

Para a lâmina foliar que apresenta extensões em cada lado da inserção do pecíolo, a terminologia proposta por Mayo (1991) tem sido bastante empregada. A divisão anterior é toda a parte da lâmina que circunda a nervura mediana e divisões posteriores são porções da lâmina que, quando presentes, se estendem basalmente em cada lado da inserção do pecíolo. Em folhas sagitadas como em Philodendron speciosum (Fig. 2a), Philodendron vargealtense (Fig. 2f) e Xanthosoma maximiliani, ou tripartidohastada como em Syngonium vellozianum (Fig. 2j), ou pinatífida como em Asterostigma luschnathianum (Fig. 21) cada divisão posterior tem uma nervura basal bem desenvolvida, a qual executa o papel de suporte mecânico, como a nervura mediana da divisão anterior. Desta nervura basal emergem nervuras laterais que recebem nomes específicos de acordo com o seu posicionamento na lâmina foliar; as nervuras acroscópicas emergem da nervura basal em direção à margem externa das divisões posteriores e as nervuras basioscópicas em direção à margem interna destas divisões (Fig. 2a). O número destas nervuras é um caráter importante para o reconhecimento de muitas espécies. Em folhas cordadas e cordado-sagitadas a nervura basal pode ser curta ou ausente, com as nervuras laterais primárias surgindo, independentemente, na base da nervura mediana.

Folhas elaboradamente perfuradas ou fenestradas, por crescimento diferenciado da margem, ou por necroses de partes da lâmina, ou ainda a combinação de ambos os processos, ocorrem em alguns gêneros como Monstera e pôde ser observado nas duas espécies encontradas no PERD: M. adansonii e M. praetermissa (Fig. 2g). Heterofilia é uma outra característica notável e, algumas vezes, útil taxonomicamente, que está presente em muitos gêneros como: Asterostigma, Philodendron, Monstera, Rhodospatha e Syngonium. A heterofilia ocorre tanto na ontogenia como em associação com ramos flageliformes. A heterofilia pôde ser observada em Syngonium vellozianum que possui folhas sagitadas quando o indivíduo é juvenil ou as folhas estão associadas a ramos flageliformes (Fig. 1h) e tripartido-hastadas quando adulto (Fig. 2j). Outro exemplo de heterofilia é Asterostigma luschnathianum que possui folha sagitada quando juvenil (Fig. $2 \mathrm{~m}$ ) e pinatífida (Fig. 21).

Outras estruturas foliares são a lígula e o pulvino ou genículo. A lígula foi relatada por Engler (1878), como uma extensão da bainha, formando um apêndice livre no ápice, entre a bainha e o limbo, assim como ocorre nas Poaceae. A lígula foi verificada apenas em Philodendron propinquum (Fig. 2e). O genículo, de acordo com Mayo et al. (1997), é semelhante ao pulvino das Leguminosae, mas ocorre geralmente na porção distal do pecíolo, em quase todas as Pothoideae e Monsteroideae, permitindo uma reorientação da folha. Algumas espécies apresentam um segundo genículo na porção proximal do pecíolo, mas nas espécies do PERD, apenas o genículo na porção distal foi verificado em Anthurium pentaphyllum, Anthurium scandens, Heteropsis flexuosa, Heteropsis salicifolia, Monstera adansonii, Monstera praetermissa e Rhodospatha sp. (Fig. 2i). O colênquima, devido à ocorrência de células de paredes espessadas mas não lignificadas, é um tecido de suporte em órgãos aéreos que apresenta uma notável plasticidade. Gonçalves et al. (2004) apresentaram três padrões de distribuição de colênquima para a região central do pecíolo: colênquima ausente com esclerênquima como principal tecido de suporte; anel periférico de colênquima (padrão philodendróide) e cordões de colênquima (padrão colocasióide). Para alguns gêneros que não apresentam colênquima na região central do pecíolo este pode ser restrito ao genículo, como ocorre em Anthurium (Gonçalves et al. 

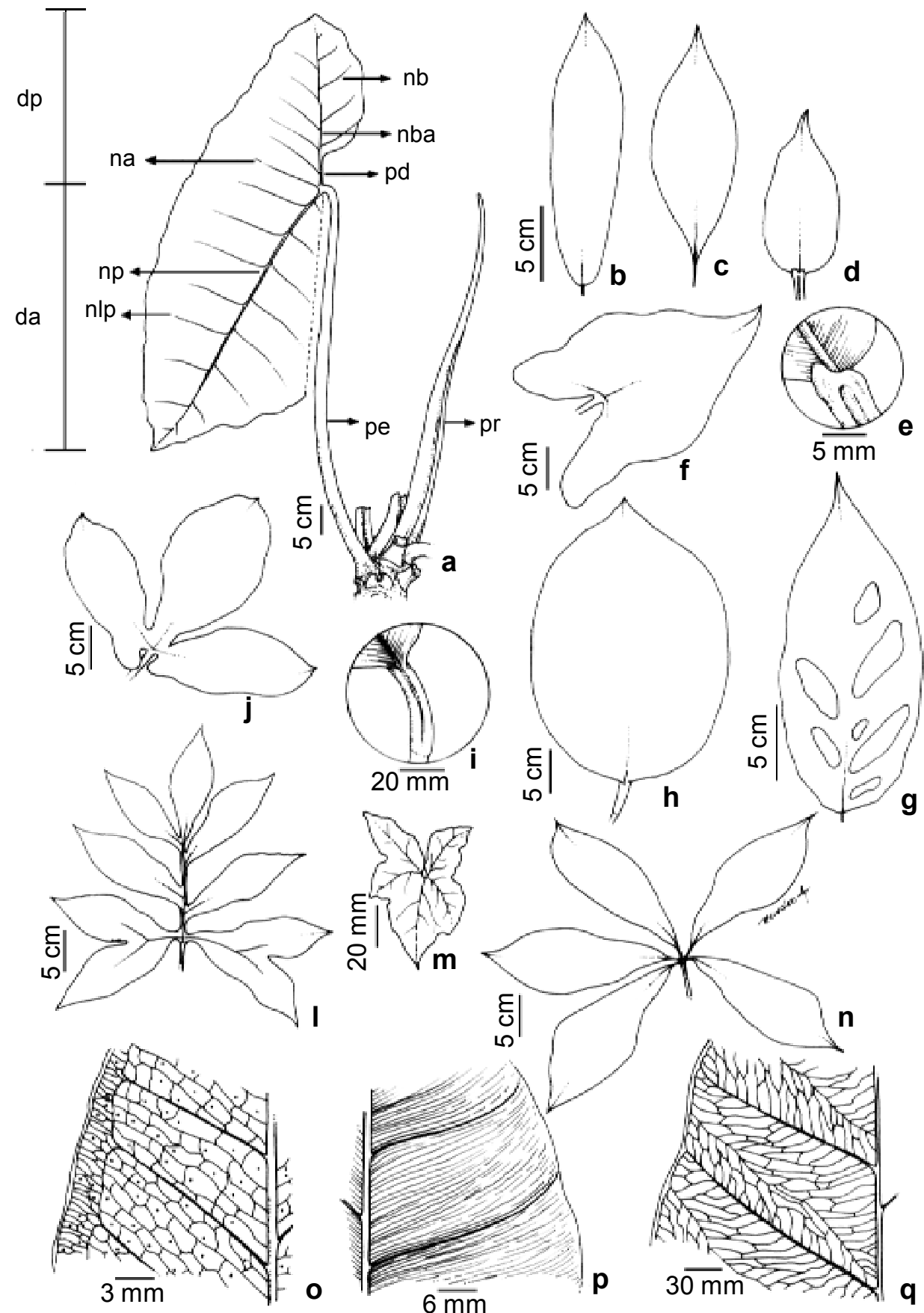

Figura 2 - Morfologia foliar: a. divisões da folha sagitada, $\mathrm{da}=$ divisão anterior, $\mathrm{dp}=$ divisão posterior, $\mathrm{pd}=$ porção desnuda da nervura basal, $\mathrm{pe}=$ pecíolo, $\mathrm{pr}=$ profilo, na $=$ nervuras acroscópicas, $\mathrm{nb}=$ nervuras basioscópicas, $\mathrm{nba}=$ nervura basal, $\mathrm{nlp}=$ nervura lateral primária, $\mathrm{np}=$ nervura principal ou central, Philodendron speciosum (Temponi 179); b. lâmina obovada, Heteropsis flexuosa (Temponi 138); c. lâmina elíptica, Anthurium scandens (Temponi 193); d-e. Philodendron propinquum (Temponi 181), d. lâmina ovada, e. lígula; f. lâmina sagitada, Philodendron vargealtense (Temponi 223); g. lâmina ovada, fenestrada Monstera praetermissa (Temponi 84); h-i. Rhodospatha sp. nov. ined. (Temponi 220), h. lâmina oblonga, i. genículo; j. lâmina tripartido-hastada, Syngonium vellozianum. (Temponi 192); 1-m. Asterostigma luschnathianum (Temponi 221), 1. lâmina pinatífida, m. lâmina jovem sagitada; n. folha palmada, Anthurium pentaphyllum (Temponi 217); o. padrão de nervação reticulado, Anthurium scandens (Temponi 193); p. padrão peniparalelinérveo, Rhodospatha sp. nov. ined. (Temponi 220); q. padrão colocasióde, Xanthosoma maximiliani (Temponi 178). 
2004).

O padrão de nervação (Figs. 2o-q) em Araceae é bastante complexo e útil na identificação de gêneros. A nervura mediana é quase sempre presente e desta saem as nervuras laterais primárias que são, geralmente, pinadas e percorrem a lâmina formando, em alguns gêneros, nervuras marginais, que se anastomosam no ápice da lâmina. As nervuras laterais secundárias, terciárias e de ordens superiores são reconhecidas por sua relativa espessura e/ou seu nível hierárquico de ramificação. As nervuras mais finas podem ser reticuladas, como em Anthurium (Fig. 2o) ou paralelas às nervuras laterais primárias, como em Philodendron e Rhodospatha (Fig. 2p). Estas últimas são referidas, geralmente, na literatura de Araceae, como paralelas ou estriadas. Mayo et al. (1997) definem o termo peniparalelinérvea, para espécies que apresentam as nervuras laterais secundárias paralelas às nervuras laterais primárias. Tal termo distingue este padrão da nervação paralela que ocorre nas gramíneas e que, em Araceae, ocorre somente em Gymnostachys. Um outro tipo de nervação é a colocasióide, que ocorre em representantes das tribos Colocasieae e Caladieae, da subfamília Aroideae de Mayo et al. (1997), ou Colocasioideae de Grayum (1990) pôde ser verificado em Xanthosoma (Fig. 2q), onde as nervuras mais finas ramificam-se em ângulo reto com as nervuras laterais primárias, arqueiam-se de maneira mais ou menos sinuosa, em direção à margem da folha, formando uma nervura interprimária, e então, finalmente, fundem-se na margem, formando uma nervura coletora submarginal.

As inflorescências podem formar um simpódio floral ou ocorrerem isoladas nas axilas foliares. A produção de inflorescências, para formar o simpódio floral, representa o desenvolvimento de unidades simpodiais curtas, consistindo de somente um profilo e uma inflorescência. A primeira é formada na axila da folha e as sucessivas inflorescências, são formadas nas axilas dos profilos (Ray 1987a).
Isto pode ser facilmente percebido quando entre o caule e uma única folha de lâmina expandida, encontram-se várias inflorescências em estádios de maturação distintos, já que se desenvolvem consecutivamente. Simpódio floral foi observado em Monstera adansonii, Philodendron vargealtense, Syngonium vellozianum e em Xanthosoma maximiliani.

Há, pelo menos, dois tipos básicos de espádice (Tabela 2): um com flores bissexuais espiraladamente dispostas em um espádice homogêneo, subtendido por uma espata não constrita, sem distinção entre tubo e lâmina (Fig. 3a). O espádice homogêneo pode apresentar flores perigoniadas como em Anthurium ou aperigoniadas como em Monstera Heteropsis e Rhodospatha. O outro tipo básico de inflorescência apresenta flores unissexuais, aperigoniadas, dispostas de forma organizada em um espádice heterogêneo, onde a zona feminina é inferior e a zona masculina superior, freqüentemente com uma ou duas zonas estéreis (Fig. 3c). Neste tipo de espádice a espata pode ser constrita ou não. A espata constrita é diferenciada em um tubo convoluto, na parte inferior e lâmina estendida, na porção superior, como pôde ser verificado em Philodendron vargealtense, Philodendron speciosum, Syngonium vellozianum e Xanthosoma maximiliani (Figs. 3b). Espécies com espádice heterogêneo e espata sem constrição também foram observadas: Philodendron propinquum e Asterostigma luschnathianum.

Flores bisexuais em Araceae podem ser perigoniadas ou aperigoniadas (Tabela 2). Em flores perigoniadas (Figs. 3d, e) as tépalas, mais ou menos carnosas e fornicadas apicalmente, quando livres, são organizadas em dois verticilos. Os estames, nestas flores e nas bissexuais nuas, como na maioria das Monsteroideae, possuem filetes achatados, anteras basifixas e conectivos inconspícuos (Figs. 3f, g). Em flores unissexuais de muitas tribos de Aroideae, como Philodendreae, o 

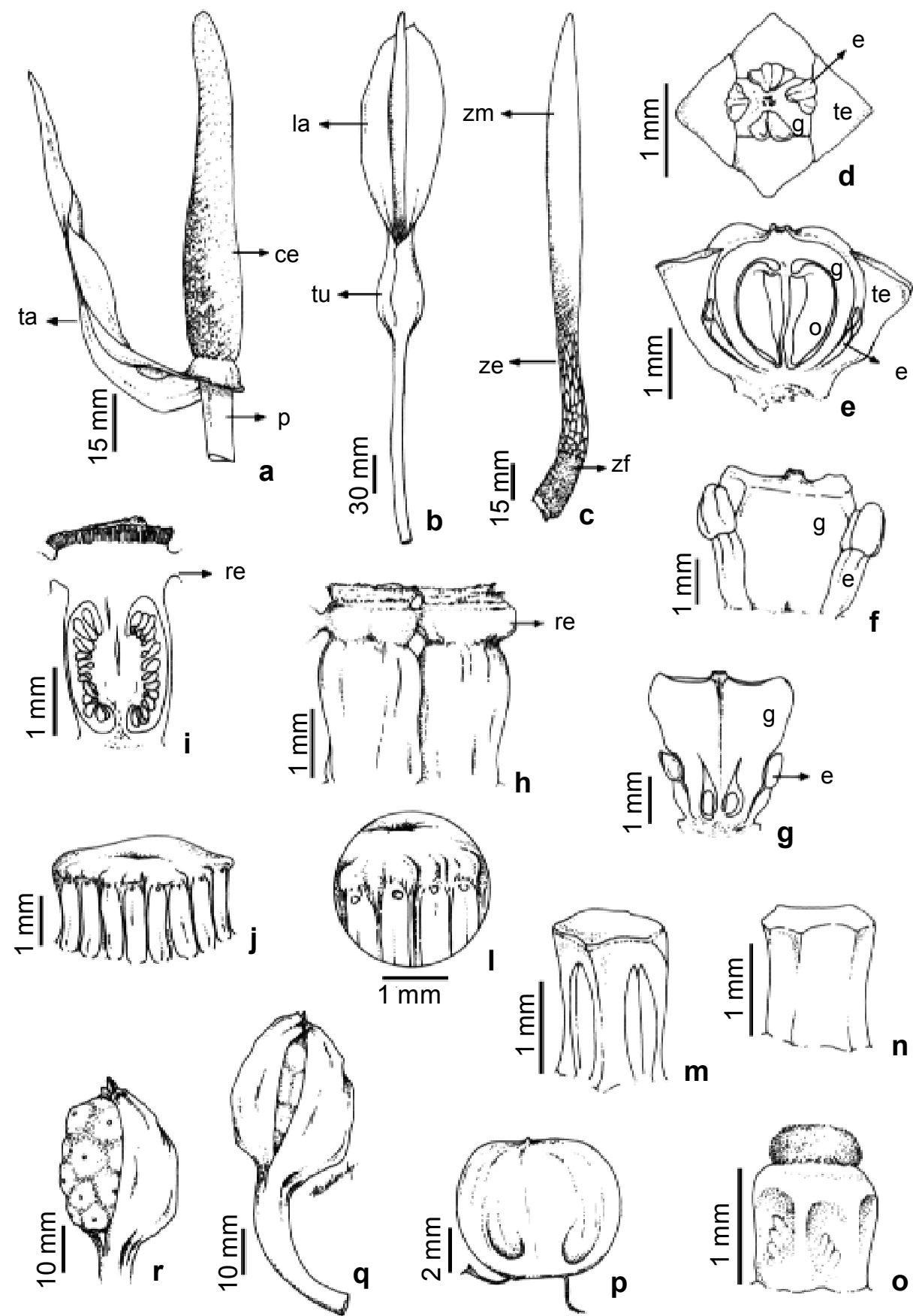

Figura 3 - Morfologia da inflorescência, flores e frutos: a. inflorescência com flores bissexuais, $\mathrm{p}=$ pedúnculo, ce=espádice homogêneo, ta=espata não constrita, Anthurium pentaphyllum (Temponi 119); b-c. Xanthosoma maximiliani (Temponi 201), b. espata, tu=tubo e la=lâmina, c. espádice heterogêneo, $\mathrm{z}=$ =zona feminina, ze=zona masculina estéril e zm=zona masculina; d-e. flor de $A$. scandens (Temponi 193), te=tépala, e=estame, g=gineceu e o=óvulo, d. vista frontal, e. corte longitudinal; f-g. flor de Heteropsis salicifolia (Temponi 102), e=estame e g=gineceu, f. vista longitudinal, g. corte longitidinal; h-l. Xanthosoma maximiliani (Temponi 201), h. visão longitudinal de flores femininas, re=região estilar, i. corte longitudinal da flor feminina, re=região estilar, $\mathrm{j}$. sinândrio, 1 . poro subapical; m-o. Philodendron vargealtense (Temponi 164), m. vista longitudinal da flor masculina, n. vista longitudinal da flor masculina estéril, o. vista longitudinal da flor feminina; p. baga isolada, Anthurium scandens (Temponi 193); q-r. bagas em sincarpia, Syngonium vellozianum (Temponi 157). 
filete é muito curto ou ausente e há um conectivo espessado e carnoso que, provavelmente, atua como osmóforo (Figs. 31, m); em Caladieae, como em Xanthososma maximiliani (Fig. 3j) e Spathicarpeae, os estames são sempre fundidos num sinândrio. As anteras são quase sempre extrorsas e as fendas longitudinais ocorrem na maioria dos gêneros de flores bissexuais e em alguns de flores unissexuais (Fig. 3m). Entretanto, fendas curtas ou poros apicais e subapicais, ocorrem geralmente em gêneros de flores unissexuais, como em Xanthosoma maximilianii (Figs. 3j, 1), uma espécie da subfamília Aroideae e, em representantes de Lasioideae.

O gineceu usualmente varia de 1-3locular, embora gineceu com mais de 3 lóculos na tribo Spathicarpeae e no gênero Philodendron seja freqüentemente encontrado. O tipo de placentação é muito variável na família: axial-apical, axial-basal, axial, apical, basal e parietal. Foram verificadas placentação axial-apical em Anthurium pentaphyllum e Anthurium scandens (Figura 3e), placentação axial-basal na maioria das espécies estudadas (Tabela 2), incluindo Heteropsis salicifolia (Fig. 3g) e placentação axial em Philodendron propinquum, Rhodospatha sp. e Xanthosoma maximilianii (Fig. 3i). Usualmente, tricomas secretores de uma substância mucilaginosa são presentes nos funículos dos óvulos de Philodendron (Mayo et al. 1997). Nas espécies encontradas no PERD, foram verificados apenas em Philodendron vargealtense. $\mathrm{O}$ estilete, na maioria dos gêneros, é inconspícuo externamente ou pouco mais largo que o ovário como em Philodendron vargealtense (Fig. 3o) mas, muito freqüentemente, há uma região estilar espessada entre os lóculos do ovário e o estigma, como na tribo Monstereae, e em Xanthosoma maximiliani. Em Monstereae, esta região é especialmente bem desenvolvida e com tricoesclereídes, como verificado para Monstera praetermissa, o que parece substituir funcionalmente o perianto, protegendo os órgãos sexuais das flores, especialmente o ovário (Mayo et al. 1997). A região estilar das flores vizinhas são fundidas em muitas espécies de Xanthosoma e isto foi verificado para $X$. maximiliani (Fig. 3h), a única espécie do gênero encontrada no PERD.

A infrutescência é usualmente cilíndrica ou globosa, com bagas parcialmente livres (Fig. 3p) ou, conatas como em Syngonium vellozianum (Figs. 3q, r), formando um sincarpo indeiscente. As sementes são geralmente embebidas em polpa mucilaginosa. Em alguns gêneros o tegumento externo torna-se mucilaginoso e em Anthurium a camada interna do pericarpo pode também ser mucilaginosa.

Vários mecanismos de proteção para o desenvolvimento do fruto e da semente foram discutidos por Madison (1977); em Monstera, a região estilar espessada e com tricoesclereídes, só se rompe na maturidade. Durante o estudo com as Araceae do PERD foi verificado que em Monstera adansonii a região estilar se rompe expondo as bagas brancas apenas quando completamente maduras. Já em Anthurium scandens e Anthurium pentaphyllum, as tépalas permanecem durante o crescimento e desenvolvimento das bagas, tornando-se completamente exposta apenas na maturidade. Em gêneros de flores unissexuais, esta função é assumida pela espata ou pelo tubo da espata. Nas espécies de Philodendron encontradas no PERD a espata que é persistente, envolve o fruto até sua maturação. Quando maduro a espata se decompõe e expõe as bagas. Em espécies como Xanthosoama maximilianii e Syngonium vellozianum que apresentam apenas o tubo persistente, envolvendo a zona de flores femininas do espádice, este se mantém até o desenvolvimento das bagas (Fig. 3q). Em Syngonium vellozianum o tubo da espata parece funcionar não apenas na proteção durante o desenvolvimento do fruto, mas também na atração dos dispersores, pois se torna alaranjado quando as bagas estão maduras. 


\section{Agradecimentos}

As autoras agradecem aos especialistas Marcus A. Nadruz Coelho, Eduardo G. Gonçalves e Simon J. Mayo pelo envio de bibliografia, valiosos esclarecimentos sobre a morfologia do grupo e sugestões na redação deste texto. Ao Reinaldo Antônio Pinto pelas ilustrações. À Fundação O Boticário/ Macarthur Foundation pelo financiamento do projeto e a CAPES pela bolsa de mestrado concedia à primeira autora.

\section{REFERÊNCIAS BIBLIOGRÁFICAS}

Andrade, I. M. \& Mayo, S. J. 1998. Dynamic shoot morphology in Monstera adansonii Schott var. klotzchiana (Schott) Madison (Araceae). Kew Bulletin 53(2): 399-417.

Croat, T. B. 1985. Collecting and preparing specimens of Araceae. Annals of the Missouri Botanical Garden 72: 252-258. . 1988. Ecology and life forms of Araceae. Aroideana 11(3): 4-55.

Croat, T. B. \& Bunting, G. S. 1979. Standardization of Anthurium descriptions. Aroideana 2(1): 15-25.

Engler, H. G. A. 1878. Araceae. In: Martius, C. F. P. von; Eichler, A. W. \& Urban, I. (eds.). Flora brasiliensis 3(2): 26-223.

Engler, H. G. A. \& Krause, K. 1920. AroideaeColocasioideae. In: A. Engler. Das Pflanzenreich 71 (IV. 23E): 1-139.

French, J. C.; Chung, M. G. \& Jur, Y. K. 1995. Chloroplast DNA phylogeny of the Ariflorae. In: Rudall, P. J., Cribb, P. J. Cuttler, D. F., Humphries. Monocotyledons: systematics and evolution. pp. 255-275. Royal Botanic Gardens, Kew.

Gonçalves, E. G.; Paiva, E. A. S. \& Coelho, M. A. N. 2004. A preliminary survey of petiolar collenchyma in the Araceae. Annals of the Missouri Botanical Garden
91(3): 473-484.

Grayum, M. H. 1990. Evolution and phylogeny of Araceae. Annals of the Missouri Botanical Garden 77: 628-697.

Holmgren, P. K; Holmgren N. H. \& Barnett, L. C. Index Herbariorum Part I: The Herbaria of the World. New York Botanical Garden, New York, 693p.

Keating, R. C. 2004. Vegetative anatomical data and its relationship to a revised classification of the genera of Araceae. Annals of the Missouri Botanical Garden 91(3): 485-494.

Madison, M. T. 1977. A revision of Monstera (Araceae). Contributions from the Herbarium Harvard University 207: 1101.

Mayo, S. J. 1991. A revision of Philodendron subgenus Meconostigma (Araceae). Kew Bulletin 46(1): 601-681.

Mayo, S. J.; Bogner, J. \& Boyce, P. C. 1997. The genera of Araceae. The Trustees, Royal Botanic Gardens, Kew, 370 p.

Radford, A. E.; Dickison, W. C.; Massey, J. R. \& Bell, C. R. 1979. Vascular plant systematics. Harper \& Row Publishers, New York, 891 p.

Ray, T. S. 1987a. Leaf types in the Araceae. American Journal of Botany. 74 (9): 1359-1372.

1987b. Diversity of shoot organization in the Araceae. American Journal of Botany 74 (9): 1373-1387

Temponi, L. G. 2001. Araceae do Parque Estadual do Rio Doce, Minas Gerais, Brasil. Dissertação de Mestrado. Universidade Federal de Viçosa, Viçosa, MG. 

